\title{
Impact of land fragmentation and soil fertility on Aus rice producers' technical efficiency in Barisal district of Bangladesh
}

\author{
A. K. M. Abdullah Al-Amin*, M. Saidur Rahman and M. I. Hossain ${ }^{1}$ \\ Department of Agricultural Economics and ${ }^{1}$ Department of Agribusiness and Marketing, Bangladesh Agricultural \\ University, Mymensingh-2202, Bangladesh, “E-mail: alaminaers@gmail.com
}

\begin{abstract}
This article determines the impact of land fragmentation and soil fertility on Aus rice producers' technical efficiency (TE) of Barisal district in Bangladesh. A total of 60 farm households from two villages were selected using stratified random sampling procedure. Detailed input and output data for the Aus were collected in May 2015. Cobb-Douglas stochastic frontier model was used to address this TE. Results indicate that the mean TE was 0.61. Among the four land fragmentation indicators two were found to be statistically significant with anticipated signs. The positive effect of the number of plots on TE implies that variation effect exceeded the management effect and the average distance from plots to homestead indicating loss of time and inconvenience in farming management as well as inefficiencies in input use. The study also used two indicators of soil fertility (i.e., share of highly fertile land and share of not highly fertile land). Between these share of highly fertile land had positive impact on TE in rice productivity. Therefore, the study includes policy implications addressing the structural causes of land fragmentation and developing effective strategies to promote soil conservation.
\end{abstract}

Keywords: Rice productivity, Land fragmentation, Soil fertility, Technical efficiency, Stochastic production frontier

\section{Introduction}

Agriculture is one of the most important sectors of Bangladesh economy. The sector contributes around 16.77 percent to the gross domestic product (GDP) of the country and employs around 47.5 percent of the total labour force. Moreover, the sector feeds up around 160 million people of the country and provides survival and nutrition for the farm households of rural areas (GoB, 2014).

Agriculture is always vulnerable and agriculture sector is highly sensitive to land fragmentation (Shafiqul, 2014; Rahman and Rahman, 2009; Wan and Cheng, 2001). Land fragmentation here refers to farming of a number of non-contiguous owned or leased plots (or parcels) of land as a single production unit (McPherson, 1982). Bangladesh is called an over populated country. In fact, her present population has come to a stage of explosion. Moreover, every year 1 percent of its arable land or 82900 hectares (ha) of crop land and everyday 221 ha of arable land is losing in Bangladesh to accommodate increased population (Bhuiyan, 2003). The country's population will be over around 190 million by 2030 when an extra 25 percent food grains will have to be produced from smaller area of cropland (Bhuiyan, 2003). High population growth results in fragmented land which intern hampers soil fertility and ultimately damages agricultural productivity. Land fragmentation is considered an impediment to efficient crop production. In addition to shrinking availability of land for farming, land fragmentation is on the rise in Bangladesh. Bangladesh is experiencing rapid decline in farm sizes coupled with an increase in the number of operational holdings. The average farm size decreased to a level ( $0.68 \mathrm{ha})$ at which it is unlikely to sustain livelihoods (Niroula and Thapa, 2005). Moreover the area under Aus rice production was 2750 thousand acres in 2010-2011 and in 2012-2013 it was 2602 thousand acres (BBS, 2013). Farmer's incentive to produce Aus rice was decreased year by year. A few studies remotely touched Aus rice efficiency in Bangladesh including Sadia and Serajul, (2012) economics of Aus rice and jute cultivation; Sarkar et al. (2013) Aus rice yield response to climate variables; and Baten and Hossain (2014) stochastic frontier model with distributional assumptions of rice.

Given this backdrop, the present study sets out to determine the impact of land fragmentation as well as soil fertility on Aus rice producers' technical efficiency (TE), using a stochastic frontier model. For land fragmentation, the study used a set of indicators, fertilizer use was measured separately by active macronutrient contents and soil fertility was measured by asking farmers' perceptions, as expressed by the share of highly fertile land and share of not highly fertile land. 


\section{Methodology}

Primary data pertains to a farm survey of rice producers collected during late 2015 in Barisal district located in the southern part of Bangladesh. The district is composed of 10 upazilas, 86 uninos, and 1,069 villages. Bakerganj upazila was selected from Barisal district. A total of 60 farm households were selected following a stratified random sampling procedure. Detailed input and output data were collected for the Aus rice of the production year 2014-2015. Among these households, a total of 45 households were producing Aus rice. For that reason, the analysis of this study use 45 households for Aus rice production. In order to measure the technical efficiency in a way consistent with the theory of production function, a Cobb-Douglas type stochastic frontier function was specified. The Cobb-Douglas form of production function has some well known properties that justify its wide application in economic literature (Henderson and Quandt, 1971). It is a homogeneous function that provides a scale factor enabling one to measure the returns to scale and to interpret the elasticity coefficients with relative ease. It is also easy to estimate and mathematically manipulate. It is less affected by multicollinearity problem and less suffered from degrees of freedom.

The explicit Cobb-Douglas stochastic frontier production function is as follows:

$\ln Y_{i}=\ln \beta_{0}+\sum_{i=1}^{10} \beta_{i} \ln X_{i}+V_{i}-U_{i}$

Where, $\mathrm{Y}=$ Output $\left(\mathrm{kg}\right.$ per farm), $X_{1}=$ Area under rice cultivation (Hectare), $X_{2}=$ Human Labour (mandays per farm), $X_{3}=$ Seed (kg per farm), $X_{4}=$ Chemical input (Pesticides) (mg per farm), $X_{5}=$ Power tiller (hours per season per farm), $X_{6}=$ Irrigation (hours per season per farm, $X_{7}=$ Urea (kg per farm), $X_{8}=$ Triple Super Phosphate (kg per farm), $X_{9}=$ Muriate of Potash (kg per farm), $X_{10}=$ Organic fertilizer (cowdung and ash) ( $\mathrm{kg}$ per farm). $\mathrm{V}$ is assumed to be independently and identically distributed random error, having $\mathrm{N}\left(0, \sigma^{2} v\right)$ distribution; and the $\mathrm{U}$ is non-negative one-sided random variable, called technical inefficiency effects, associated with the technical inefficiency of production of the farmers involved. It is assumed that the inefficiency effects are independently distributed with a half normal distribution.

The model for the technical inefficiency effects in the stochastic frontier of equation (1) is defined by

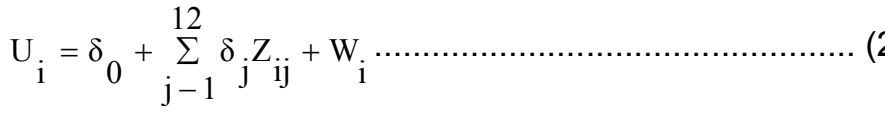

Where Z's represents age of household head, education of household head, experience in rice cultivation, household size, number of plots, average plot (parcel) size, average distance from plots to homestead, average distance from plots to main road, share of highly fertile land, share of not highly fertile land, extension service, and produced modern varieties respectively. $\delta$ 's are unknown parameters to be estimated, $W_{i}$ refers random error-term.

The parameters of the stochastic frontier production function model are estimated by the method of maximum likelihood, using computer program-FRONTIER Version 4.1.

Different variables of the inefficiency function along with their definitions are presented in Table 1.

\section{Results and Discussion}

The summary statistics of the variables gathered from the farms are reported in Table 2. The average production of Aus rice of the farm household was $1323.41 \mathrm{~kg}$ with a standard deviation of 2131.95 which indicate the large variability of production among the farmers. The average area used for rice cultivation (i.e. mean value is 0.43 hectare whereas the standard deviation is 0.55 ) represents moderate variations among households. The feature indicates that all the farmers have more or less similar amount of lands which is different scenario compare to the developed countries. 
Table 1. Variable description for inefficiency function

\begin{tabular}{lll}
\hline Variables & Unit & Data sources \\
\hline Age of household head & Year & Primary \\
Education of household head & Year & Primary \\
Experience in rice cultivation & Year & Primary \\
Household size & (Persons/hh) & Primary \\
Number of working members & (Persons/hh) & Primary \\
Number of plots & (Number) & Primary \\
Average plot (parcel) size & Hectare & Primary \\
Average distance from plots to homestead & Meter $(\mathrm{m})$ & Primary \\
Average distance from plots to main road & Meter (m) & Primary \\
Share of highly fertile land & $\%$ & Primary \\
Share of not highly fertile land & $\%$ & Primary \\
Dummy (1 if household receive extension service; 0 otherwise) & - & Primary \\
Dummy (1 if household produced modern varieties; 0 otherwise) & - & Primary \\
\hline
\end{tabular}

The labour use in case of farm operation also shows variability. Use of organic and in-organic fertilizer varied among the farmers, this may be due to lack of knowledge about proper dose of fertilizer. In developing countries like Bangladesh, farmers are not properly trained about input use. On an average the farmers were experienced with many farming years but their level of schooling was low. Fifty three percent Aus rice growers had extension contracts. Level of modern technology adoption was high, because 73 percent $A u s$ rice growers produced modern varieties of rice in addition to traditional varieties. Land fragmentation showed substantial variation. On an average, the respondent households used 3.58 plots to cultivate Aus rice. The average plot size was 0.38 hectare whereas the standard deviation is 0.52 indicate large variation in holding size.

Table 2. Descriptive statistics of variables used

\begin{tabular}{|c|c|c|c|c|}
\hline Variables used & Min & Max & Mean & SD \\
\hline \multicolumn{5}{|l|}{ Values of the production function variables } \\
\hline Prod (Kg per farm) & 6 & 13063 & 1323.41 & 2131.95 \\
\hline La (Hectare) & 0 & 3 & 0.43 & 0.55 \\
\hline Lab (Man-days per farm) & 0 & 163 & 40.82 & 32.69 \\
\hline Seed (Kg per farm) & 5 & 175 & 24.21 & 27.57 \\
\hline Pes (Mg per farm) & 0 & 5000000 & 707003.33 & 1362370.16 \\
\hline PT (Hours per season per farm) & 1 & 48 & 11.75 & 13.29 \\
\hline Irri (Hours per season per farm) & 0 & 375 & 17.10 & 59.71 \\
\hline Urea (Kg per farm) & 0 & 160 & 34.10 & 39.06 \\
\hline TSP (Kg per farm) & 0 & 60 & 4.89 & 11.85 \\
\hline MoP (Kg per farm) & 0 & 50 & 8.31 & 11.70 \\
\hline CA (Kg per farm) & 0 & 1120 & 63.69 & 244.41 \\
\hline \multicolumn{5}{|l|}{ Values of technical inefficiency model variables } \\
\hline Age (Year) & 22 & 70 & 49.40 & 11.43 \\
\hline Edu (Year) & 0 & 18 & 5.82 & 3.74 \\
\hline Exp (Year) & 3 & 55 & 23.38 & 13.03 \\
\hline Hhsize (Persons/ hh) & 3 & 11 & 5.42 & 1.82 \\
\hline Nplots (Number) & 1 & 12 & 3.58 & 2.69 \\
\hline APsize (Hectare) & 0 & 3 & .38 & 0.52 \\
\hline Distph (Meter) & 5 & 3441 & 574.79 & 731.20 \\
\hline Distpmr (Meter) & 6 & 4350 & 526.45 & 957.67 \\
\hline Shfl (Percent) & 0 & 100 & 35.26 & 32.65 \\
\hline Snhfl (Percent) & 0 & 100 & 54.54 & 35.89 \\
\hline Dext (Dummy; 1 if household receive extension service; 0 otherwise) & 0 & 1 & 0.53 & 0.51 \\
\hline Dmv (Dummy; 1 if household produced modern varieties; 0 otherwise) & 0 & 1 & 0.73 & 0.45 \\
\hline
\end{tabular}

Source: Authors' calculation based on survey data, 2015. 
Table 3 shows the simultaneous estimation of the maximum likelihood estimates for the parameters of the Cobb-Douglas stochastic production frontiers and technical inefficiency effect model. Since the functional form is Cobb-Douglas; the parameters can be interpreted as elasticity. The coefficient of land is positive and statistically significant at 1 percent level implying using more land significantly increases the productivity. Seed, irrigation hour as well as cowdung and ash also had statistically significant positive effect implying Aus rice productivity could increase with expanding these inputs.

The bottom rows of the Table 3 represent the results of the error terms specified earlier in equation (1). Gamma $(\gamma)$ is the ratio of variance of farm specific TE to the total variance of output and has a value between zero and one. Both $\gamma$ and $\sigma^{\mathbf{2}}$ are reparameterized versions of $\sigma_{v}^{2}$ and $\sigma_{2}^{2}$, i.e., $\sigma^{2}=\sigma_{u}^{2}+\sigma_{u}^{2}$ and $\gamma=\sigma_{u}^{2} /\left(\sigma_{w}^{2}+\sigma_{u}^{2}\right)$. The estimates of the variance parameter $\sigma^{\mathbf{2}}$ for Aus rice is 0.94 . On the other hand, the estimate of variance parameter $\gamma$ is 0.98 . From the result it is evident that $\sigma^{2}$ and $\gamma$ are significantly different from zero, indicating that inefficiency significantly affected the level and variation of output of the surveyed farm households. The high value of $\gamma$ indicates the presence of significant inefficiencies in the production of Aus rice crop. Regression results for equation (2) are presented in the second part of Table 3. From the sign it is evident that, farmers age had a negative impact on TE of Aus rice production. Since the endogenous variable of the inefficiency model in equation 2 , is defined in terms of technical inefficiency, so the positive sign on the coefficient indicates negative impact on TE (i.e., variables associated with the negative coefficient will have a positive impact on TE and vice-versa). The possible explanation is that older farmers are likely to be more conservative and less receptive to new technology and practices, thereby having more inefficiency in rice production. The result confirms with Wadud and White (2000). More experienced farmers were technically efficient in Aus rice production, but technically inefficient in dry season rice production. More experienced farmers have more knowledge of their land and traditional practices.

Among the four land fragmentation indicators (the number of parcels, average plot size, distance from plots to homestead and distance from plots to main road) two were found to be statistically significant with anticipated signs. The positive effect of the number of plots on TE in Aus rice production implies that large number of plots may enable farmers to benefit from variation in local agro-climatic conditions, such as sunshine, precipitation, slope or soil depth, by distributing their own labour over the seasons and tuning the choice of rice varieties to these conditions (i.e., variation effect exceeded the management effect). This confirms with Tan et al. (2010) and Shetlund et al. (2002) that TE is higher for farmers who cultivate more rice plots. The average distance from plots to homestead on TE had the expected sign, indicating loss of time and inconvenience in farming management as well as inefficiencies in input use. In the same time access to agricultural services such as field days, field visits, smooth communication and extension service and access to value able information would be cut off (i.e., representing the remoteness) and thereby negatively affecting the TE.

The share of highly fertile land had positive impact on TE. As the share of highly fertile land increase TE will increase. Therefore soil fertility had a positive impact on TE on the study areas. Rahman (2003) revealed that farmers located at fertile regions perform significantly better than their peers in less fertile regions, thereby reinforcing the argument that improving in soil fertility is a crucial element in increasing productivity. Sherlund et al. (2002) also confirms this. The extension service had statistically significant positive impact in Aus rice production as expected, in Bangladesh extension service is growing fastly. Rahman and Rahman (2009) also confirms this. Farmers have to invest their intensive care on the operating plots, that require some guidelines. In the study areas farmers had extension contract and this contract had positive correlation with TE. 
Abdullah Al-Amin et al.

Table 3. Results of frontier function model with Aus rice producers 'technical inefficiency determinants

\begin{tabular}{|c|c|c|c|c|}
\hline Production frontiers & Parameter & Coeff & T-ratio $^{a}$ & Sig. ${ }^{b}$ \\
\hline Constant & $\beta_{0}$ & 6.4957 & 12.9702 & $* * *$ \\
\hline $\ln (\mathrm{La})$ & $\beta_{1}$ & 0.3917 & 3.6430 & $* * *$ \\
\hline In (Lab) & $\beta_{2}$ & -0.0658 & -0.6860 & \\
\hline In (Seed) & $\beta_{3}$ & 0.3814 & 3.7567 & *** \\
\hline In (Pes) & $\beta_{4}$ & 0.0026 & 0.2478 & \\
\hline $\ln (\mathrm{PT})$ & $\beta_{5}$ & 0.0695 & 0.8248 & \\
\hline In (Irri) & $\beta_{6}$ & 0.0927 & 2.4031 & $* *$ \\
\hline In (Urea) & $\beta_{7}$ & 0.0329 & 0.5289 & \\
\hline In (TSP) & $\beta_{8}$ & -0.0018 & -0.0277 & \\
\hline In (MoP) & $\beta_{\mathrm{g}}$ & -0.0159 & -0.2233 & \\
\hline $\ln (\mathrm{CA})$ & $\beta_{1 \mathrm{a}}$ & 0.0724 & 1.9103 & * \\
\hline Inefficiency function & & & & \\
\hline Constant & $\delta_{\mathrm{a}}$ & -0.3978 & -0.3592 & \\
\hline Age & $\delta_{1}$ & 0.0819 & 2.0061 & * \\
\hline Edu & $\delta_{2}$ & 0.1552 & 1.4274 & \\
\hline Exp & $\delta_{n}$ & -0.1430 & -4.2991 & $* * *$ \\
\hline Hhsize & $\delta_{4}^{n}$ & 0.3546 & 1.5236 & \\
\hline Nplots & $\delta_{5}$ & -0.4027 & -2.0578 & ** \\
\hline APsize & $\delta_{6}$ & -0.0903 & -0.0911 & \\
\hline Distph & $\delta_{7}$ & 0.0014 & 1.9702 & * \\
\hline Distpmr & $\delta_{\mathrm{g}}$ & 0.0001 & 0.2102 & \\
\hline Shfl & $\delta_{q}$ & -0.0563 & -3.6890 & $* * *$ \\
\hline Snhfl & $\delta_{1 \mathrm{a}}$ & -0.0191 & -1.6534 & \\
\hline Dext & $\delta_{11}$ & -1.8244 & -2.4789 & $* *$ \\
\hline Dmv & $\delta_{12}$ & -0.0323 & -0.0343 & \\
\hline Sigma-squared & $\sigma^{2}=\sigma_{v}^{2}+\sigma_{u}^{2}$ & 0.9435 & 2.6688 & $* *$ \\
\hline Gamma & $\gamma=\sigma_{u}^{2} /\left(\sigma_{v}^{2}+\sigma_{u}^{2}\right)$ & 0.9756 & 49.9142 & $* * *$ \\
\hline $\begin{array}{l}\text { log likelihood } \\
\text { LR test of the one-sided error } \\
\text { No. of observations }\end{array}$ & & $\begin{array}{c}-21.3532 \\
70.4940 \\
45\end{array}$ & & \\
\hline
\end{tabular}

Source: Authors' calculation based on survey data, 2015.

a With (n-k) degrees of freedom the tabulated value of $t$ for Aus rice are 1.6896 at 10 percent level; 2.0301 at 5

percent level and 2.7238 at 1 percent level.

$b^{* * *}$ significant at 1 percent level $(p \leq 0.01)$

** significant at 5 percent level $(p \leq 0.05)$

${ }^{*}$ significant at 10 percent level $(p \leq 0.10)$

Table 4 shows the technical efficiency scores of the sampled farmers. The mean TE estimated for the Aus rice farmers is 0.61 with standard deviation of 0.28 , indicating that there is substantial inefficiency in farming operations for the sampled farmers. From the results it is evident that in the short run, there is enough room to increase rice production by improving TE alone with no additional use of resources. 
Table 4. Summary statistics of efficiency estimates

\begin{tabular}{cc}
\hline TE scores & Aus season rice \\
Min & 0.01 \\
Max & 0.96 \\
Mean & 0.61 \\
SD & 0.28 \\
\hline
\end{tabular}

Table 5 shows that only one among the 45 Aus season rice producers operated at an efficiency level higher than 95 percent. On the other hand, 24 percent of the respondents in Aus rice production operated at TE level between 80 to 90 percent. The TE scores suggest that on an average majority of the respondents were able to obtain a TE level below 50 percent. For more detailed view, the distribution of TE estimates is given in the following Fig. 1. However, households with low efficiency levels can realize a substantial increase in TE by improving experience, number of plots and extension contact.

Table 5. Distribution of technical efficiency scores for Aus rice production system

\begin{tabular}{lcccccccc}
\hline Rice type & & \multicolumn{7}{c}{ Technical efficiency scores } \\
\cline { 3 - 8 } & & $<0.50$ & $0.50-0.60$ & $0.60-0.70$ & $0.70-0.80$ & $0.80-0.90$ & $0.90-0.95$ & $>0.95$ \\
\hline \multirow{2}{*}{ Aus rice } & No. of cases & 15 & 3 & 6 & 5 & 11 & 4 & 1 \\
& Percentage & 33.33 & 6.67 & 13.33 & 11.11 & 24.44 & 8.89 & 2.22 \\
\hline
\end{tabular}

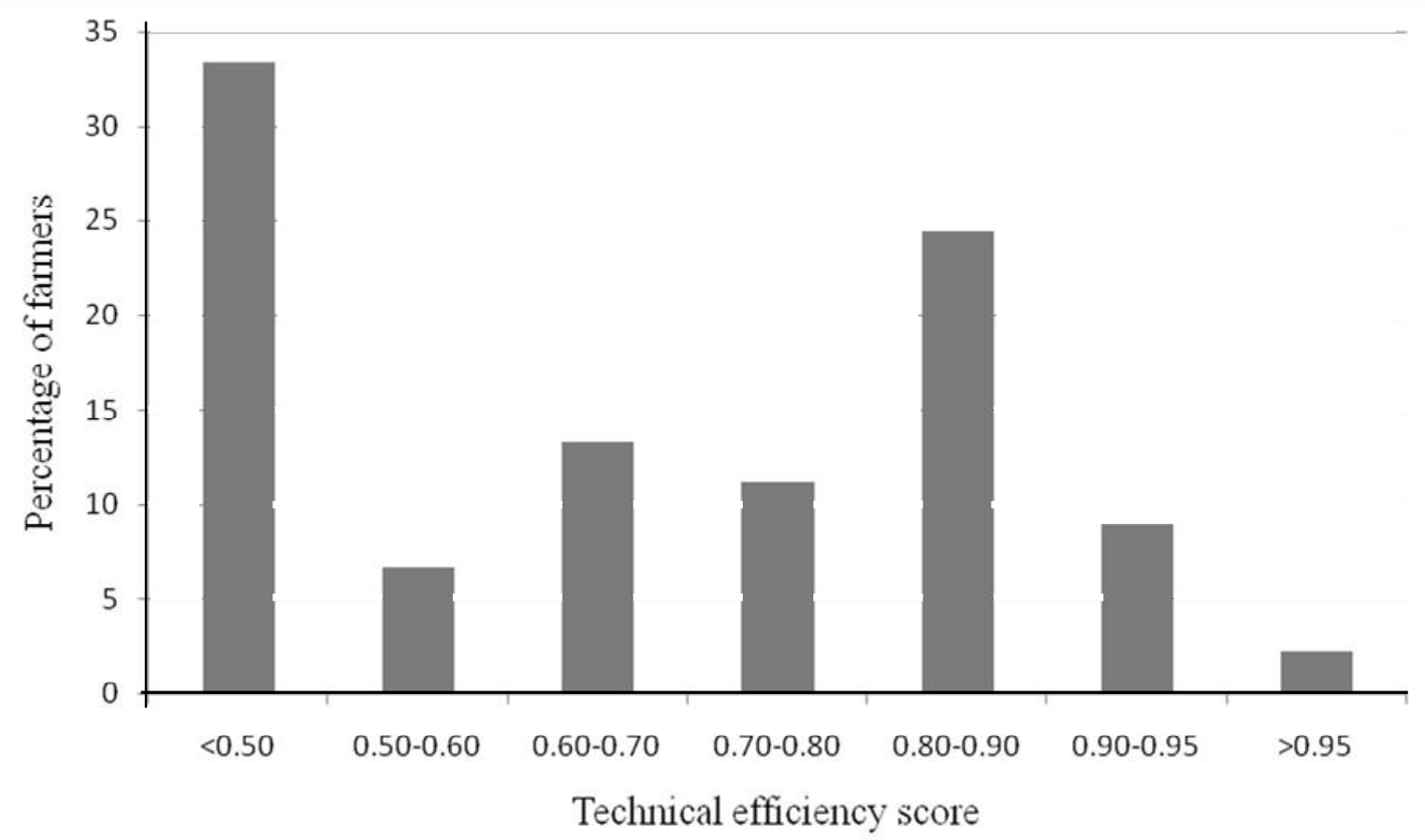

Fig. 1. Distribution of technical efficiency estimates for the Aus rice producers 


\section{Conclusion and policy Recommendations}

The mean technical efficiency was sixty one percent indicating that farmers can increase efficiency around 39 percent which is equivalent about $516.1299 \mathrm{~kg}$ yields per farm. So attention should be given in overall management of the farm, especially focusing on the inefficiency variables. Medium and low fertile land needs intensive cultivation through proper care that ensured higher TE efficiency. The findings of the study also showed that land fragmentation was one of the significant factors in explaining TE among farmers. The number of plots had positive effects on TE. The distance between homestead and plots was observed to have a statistically significant negative impact on TE. The study also reveals that the share of highly fertile land had positive impacts on TE. The adverse effects of land fragmentation should be resolved by policy instruments. Based on the findings of the study, policies are taken towards addressing the structural causes of land fragmentation. These include rethinking the law of inheritance, regulations to prevent land fragmentation.

\section{References}

Baten, A. and Hossain, I. 2014. Stochastic Frontier Model with Distributional Assumptions for Rice Production Technical Efficiency. J. Agr. Sci. Tech., 16: 481-496.

BBS (Bangladesh Bureau of Statistics), 2013. Statistical Yearbook of Bangladesh, Bangladesh Bureau of Statistics, Statistics Division, Ministry of Planning, Government of the People's Republic of Bangladesh, Dhaka.

Bhuiyan, M. 2003. Has Urbanization Caused Agricultural Land Loss? The Daily Star, November 12003.

GoB (Government of the People's Republic of Bangladesh) 2014. Bangladesh Economic Review 2008. Ministry of Finance, Government of the People's Republic of Bangladesh, Dhaka.

Henderson, J.M. and Quandt, R. 1971. Microeconomic Theory, McGraw-Hill, New York, 106-113 pp.

McPherson, M.F. 1982. Land Fragmentation: A Selected Literature Review. Development Discussion Paper No. 141. Harvard Institute for International Development, Harvard University.

Niroula, G.S. and Thapa, G.B. 2005. Impacts and Causes of Land Fragmentation, and Lessons Learned from Land Consolidation in South Asia. Land Use Policy 22: 358-372.

Rahman, 2003. Profit Efficiency among Bangladeshi Rice Farmers. Food Policy 28(5-6): 487-503.

Rahman, S. and Rahman, M. 2009. Impact of Land Fragmentation and Resource Ownership on Productivity and Efficiency: The Case of Rice Producers in Bangladesh. Land Use Policy, 26(1): 95-103.

Sadia, A. and M. Serajul, I. 2012. Economics of Aus Rice (Oryza sativa) and Jute (Corchorus olitorius) Cultivation in Some Selected Areas of Narsingdi District of Bangladesh. The Agriculturists, 10 (2): 90-9.7

Sarker, M. A. R., Alam, K. and Gow, J. 2013. How Does the Variability in Aus Rice Yield Respond to Climate Variables in Bangladesh? J Agro Crop Sci, 199: 189-194.

Shafiqul, M.I. 2014. Study on Impact of Land Fragmentation in Agriculture-A Case of Rajshahi District, Bangladesh. International Journal of Recent Research in Social Sciences and Humanities (IJRRSSH), 1(1): 54-61.

Sherlund, S.M., Barrett, C.B. and Adesina, A.A. 2002. Smallholder Technical Efficiency Controlling for Environmental Production Conditions. Journal of Development Economics, 69: 85-101.

Tan, S., Heerink, N., Kuyvenhoven, A. and Qu, F. 2010. Impact of Land Fragmentationon Rice Producers' Technical Efficiency in South-East China. Wageningen Journal of Life Sciences 57: 117-123.

Wadud, M.A. and White, B. 2000. Farm Household Efficiency in Bangladesh: A Comparison of Stochastic Frontier and DEA Methods. Applied Economics 32(13): 1665-1673.

Wan, G.H., Cheng, E.J. 2001. Effects of Land Fragmentation and Returns to Scale in the Chinese Farming Sector. Applied Economics, 33(2): 183-194. 